\title{
EL ESTABLECIMIENTO DE LA INQUISICIÓN EN SEVILLA Y SUS CONSECUENCIAS ECONÓMICAS
}

Juan Gil

A Andrés Bernal, cura de los Palacios, debemos una de las más bellas y dramáticas descripciones de la expulsión de los judíos de los reinos de Castilla. Ahora, al honrar la memoria de Juan Collantes de Terán, no parece inoportuno hurgar en el pasado de su ciudad natal, recordando otros episodios y lances preparatorios del exilio que son quizá menos pintorescos, pero no menos trágicos para el porvenir de Sevilla y de sus habitantes, sobre la base de una documentación que no creo haya sido utilizada en su totalidad con este objeto.

Los libros de cuentas, en efecto, permiten reconstruir una serie de peripecias de importancia extrema, dado que a partir de ellas se puede calibrar el balance que tuvo en la economía municipal la primera desbandada de los cristianos nuevos ante la implantación del tribunal de la Inquisición en Sevilla ${ }^{1}$. Vienen a contar, en definitiva, las en teoría aburridas partidas contables que el mayordomo Juan de Sevilla ${ }^{2}$ tuvo que hacer frente a una situación económica tan adversa,

1 Para todo lo referente al memorial de Sevilla utilizo la Relaçión de escripturas que pasaron sobre el descuento que se fizo al mayordomo Juan de Sevilla de las ccclxxx ${ }^{\circ} U \operatorname{ccclxxx}^{\circ} \mathrm{v}$, conservado en el Archivo municipal de Sevilla, papeles del mayordomazgo, año de 1484. El documento fue editado íntegramente por J. de M. Carriazo, «La Inquisición y las rentas de Sevilla», Homenaje a Don Ramón Carande, Madrid, 1963, II, p. 100 ss.

2 Arrendó la mitad de las rentas de los propios con el cargo de mayordomo por tiempo de cinco años, que comenzaron a correr desde el 1 de julio de 1480. Su puja, presentada el 2 de agosto de 1480 fue de un cuarto líquido, simple y verdadero, sin condición alguna, en cada uno de los cinco años, sobre 1.541.500 mrs. en que tenían las dichas rentas Alemán Pocasangre y Tomás de Jaén, esto es, 1.926 .937 mrs. anuales, unos 400.000 mrs. más. El 24 de agosto dio por fiador a Alfonso Núñez de Toledo, vecino en la collación de Santa María, por cuantía de 1.000.000 mrs. La mitad fue traspasada a Tomás de Jaén, obligándose éste el 14 de septiembre de 1480 (A. M. S., Mayordomazgo, 1480). La insospechada puja de Juan de Sevilla representa una maniobra clara contra los conversos. En efecto, el cabildo había arrendado la renta de los propios con el mayordomazgo a Tomás de Jaén y a Alemán Pocasangre por plazo de diez años (1 de julio de 1475 a 1 de julio de 1485); pero el 30 de junio de 1479 Diego de Merlo, el asistente, y el cabildo sentenciaron que se hiciera nueva puja y se les diese por recibida a Tomás de Jaén y a Alemán Pocasangre la cuarta parte (= 335.375 mrs.) de 
que se vio forzado a presentar por medio del escribano Alfonso García de Laredo una petición al cabildo el lunes 2 de septiembre de 1482. En ella exponía que la última pestilencia de 1481 había causado grandes daños a la ciudad, castigo evidente de Dios a los grandísimos pecados de sus moradores; pero a la mortandad se unía otro grave motivo de preocupación, debido éste a otras razones más humanas; en este punto conviene dejar la palabra al propio hacendista para que nos explique que su preocupación provenía

por cabsa del absentamiento que d'esta çibdad e de su tierra se fueron los conversos por la inquisiçión que en esta çibdad se fizo e faze contra ellos, los cuales dichos conversos eran los prinçipales arrendadores que arrendavan e acostunbravan arrendar las dichas rentas, en tal manera que a causa suya se saneava el cargo del dicho mayordomazgo; pero después que ellos se fueron e absentaron, todas las más de las dichas rentas se perdieron, espeçial en el cuerpo d'esta çibdad, segund a todos está notorio. E no tan solamente piérdense ${ }^{3}$ las dichas rentas, mas de lo que me devían me llevaron grandes contías de mrs., en tanto grado que doy fe a vuestra merçed [el asistente de Sevilla] que más de ochoçientas mill mrs. me levaron; e de más se pierde en cada un año más de quinientas mill mrs. en este dicho mayordomazgo.

Por todo ello pedía Juan de Sevilla que, usando de misericordia y piedad, los regidores se portasen con él como padres con sus hijos, prestándole la ayuda que merecían sus grandes servicios a la ciudad. Fueron encargados de hacer información al respecto el alcalde mayor Martín Fernández Cerón y el veinticuatro Diego de Fuentes, información que, acompañada de un escrito de Juan de Sevilla, fue leída al cabildo, reunido el 20 de septiembre de 1482. En ella el mayordomo volvía’a presentar las mismas consideraciones. En primer lugar,

los arrendadores que arrendavan estas rentas heran conversos e ellos e sus padres las solían arrendar e mantener en ellas, e porque los mayordomos les sobreseían las pujavan; e así ivan de un año en otro e hera propio su ofiçio e bevir. $\mathrm{E}$ agora ay pocos que en ellas fablen, porque no son onbres en ello usados como los absentes heran.

En segundo término se exponía una triste y desoladora realidad: «los tratos de la tierra han çesado». A esta desgracia se unía en tercer lugar la huída de los conversos, llevándose más de 600.000 mrs. de los arrendamientos sin remedio posible por parte suya, pues «comoquier que procuró de aver recurso a los bienes de algunos d'ellos, le fue inpedido por debdas que los tales devían al señor cardenal». Por fin, en 1481 las rentas se habían arrendado en menos que los años anteriores por causa de la fuga de los conversos y de la pestilencia: en el año de 1480 habían montado 2.072.800 mrs., frente a los $1.473 .000 \mathrm{mrs}$. del año de 1481 .

las rentas por los seis años que quedaban de arrendamiento (que montaba 135.375 mrs. anuales, quedando netas de puja 200.000 mrs.); el 16 de enero de 1480 les tomaron las cuentas Diego de Merlo, el licenciado Pedro de Santillán, Roelas y Francisco Fernández de Sevilla (cf. A. M. S., Mayordomazgo, 1479-1480). Jaén y Pocasangre pusieron pleito al cabildo, pues en la ley del cuaderno por el que arrendaban las rentas se decía que, una vez rematadas, no se podía recibir puja ni mayor ni menor; se replicó que no había tal condición en la obligación que se había hecho con Jaén y Pocasangre. Por tanto, fue confirmado Juan de Sevilla por el rey el 22 de septiembre de 1480 .

3 Así corrijo el «perdiesen» que se lee en las dos copias (mejor que «perdíanse»). 
Como el mayordomo fue requerido a que verificase información, se procedió a hacer la probanza oportuna. Pues bien, todos los testigos presentados por Juan de Sevilla, tras jurar en forma debida,

dixeron por sus dichos e depusiçiones que, entrante Cuaresma del año de ochenta e uno, algunos días poco más o menos, se fueron e se absentaron çiertos de los dichos arrendadores, cuyos nonbres son éstos que se siguen:

- Alvar López de Luçena, arrendador del diezmo del azeite de Alcalá.

- Françisco de Caçalla, arrendador del almoxarifadgo de Salteras.

- Lope de Molina e Juan Elamo, arrendadores de las barcas de Villanueva.

- Manuel Guillén, arrendador de parte del peso de las mercadorías.

- Alfonso de la Barrera, arrendador del almoxarifadgo d'Escaçena.

- El dotor Juan Rodríguez, arrendador de los exidos de Sevilla.

- Pero Mexía, escudero de Alonso de las Casas, arrendador del molino del Sohoril.

- Luis Bella, arrendador de las tavernerías e caça e freideras.

- Luis de Andújar, arrendador de las calupnias de leña e carbón.

- Ruy García Abarrox, arrendador de parte de la venta del peso.

- Gómez de Córdova, arrendador de alvaláes e çevada remojada.

- Juan de Rojas, arrendador de las calunias de teja e ladrillo.

- Pedro de Gibraleón, jurado, arrendador de las cargas.

- Luis Sánchez, canbiador, e Andrés Abarrox, arrendadores del entrada del vino.

— Diego de Ubeda, arrendador de la guarda del alhóndiga.

- Juan de Andújar, arrendador de çierta parte de la dicha renta.

- Juan de Caçalla, arrendador de parte de la dicha renta del peso.

- Juan Ximénez Abenbono, arrendador de la renta de las varas.

- Fernando de Eçija, buticario, e Juan de Sevilla Tapón, arrendadores de las tierras vacadas.

- Rodrigo de Jahén e Bernabé Gonçalez Quemado, arrendadores de parte de la renta de las islas e marismas.

- Canpoverde e Juan Tapón, arrendadores de la mitad de la dicha renta.

- Ferrando de las Casas e su fijo, arrendadores de la mitad del entrada del vino.

Los cuales dichos arrendadores absentados dixo el señor mayordomo ante nos que le devían e estavan por pagar las dichas seisçientas e veinte mill mrs.

El cabildo decidió que Juan de Sevilla procurase cobrar «lo más que ser pudiere» de los bienes de los ausentados, así que el 30 de abril de 1483 volvió a insistir el apurado mayordomo en sus argumentos. Su apremio tuvo por efecto que el bachiller Bartolomé de Herrera y el letrado de la ciudad Luis Sánchez respondiesen que habían entendido en el negocio, dando su parecer en un escrito que fue leído a continuación al cabildo, y que en sustancia se reducía a lo siguiente: por una parte argüían los leguleyos que el mayordomo no pedía justicia, porque en su deber estaba el cuidado de arrendar las rentas a personas «abonadas e contiosas e resçebir d'ellas buenas fianças»; por otra parte concluían que el caso de la inquisición era inopinado, por lo que procedía el descuento; para su evaluación proponían que se hiciera 
informaçion qué tanto pueden montar e montan los intereses que ha avido y pudo aver de los dichos derechos en estos dos años (1481-1483) por razón del ofiçio de la dicha mayordomía, e lo que montaren los derechos... se han de sacar del menoscabo que en las dichas rentas ovo; porque d'ello se deve fazer cargo al dicho jurado con lo otro que montaron las rentas de los dichos dos años. E esto descontado dévese moderar el dicho descuento por manera que la çibdad del todo no pierda lo que monta el daño que ha venido en las dichas rentas, pues qu'el dicho jurado pudiera perder en estas rentas aunque no fuera por esta cabsa alguna cosa por otro caso fortuito..., y ni mesmo el dicho jurado aya de pagar tan grand suma de pérdida.

Encargó el cabildo que entendiesen en el negocio con el letrado el alguacil Martín Cerón y Pedro de las Roelas. Así, el 27 de agosto se leyó otro escrito, firmado por Luis Sánchez, en el que se sugería que al mayordomo se le hiciera descuento de las dos terceras partes de lo que se hallase que montaba la pérdida del año 1482, y que la otra tercera parte corriera a riesgo de Juan de Sevilla. A este parecer se conformaron los oficiales. Por fin, el 8 de abril de 1485 Pedro de Rojas, el lugarteniente de asistente, y el veinticuatro Fernando de Medina de Nuncibay fijaron el descuento en $385.385 \mathrm{mrs}$., argumentando: «que se le descuente de lo que toca a la mitad de su parte del dicho mayordomadgo lo que monta la puja que fizo en uno de los dichos çinco años», es decir, la cantidad arriba expresada.

Mientras la petición seguía su curso, la ciudad continuó por su parte teniendo problemas con su erario. En efecto, por la Virgen de agosto de 1481 venció el plazo de pagar al tesorero de la Hermandad, García del Castillo, una suma de 2.900.000 mrs. Para la recaudación se fijaron ciertas exacciones extraordinarias que se encargaron de cobrar Tomás de Jaén y Alemán Pocasangre como mayordomos de la ciudad. Se dio el caso, sin embargo, de que

algunos de los arrendadores, en quien los dichos mayordomos libraron al dicho tesorero de la Hermandad çiertas contías de mrs. en cuenta de los dichos dos cuentos e nueveçientos mill mrs., fizieron quiebra en las rentas que tenían, en contía de noventa mill e quinientos e sesenta e siete mrs.

Por tanto el cabildo decidió que sufragasen tal cantidad a medias los mayordomos de su bolsillo, por considerarlos culpables en última instancia de la falta de pago, y ello con el mismo pretexto esgrimido anteriormente: «por no aver tomado las fianças que devían». He aquí, pues, como continuaba resintiéndose la hacienda municipal de las huidas de los arrendadores, cuyo nombre se deja en silencio y cuyo impago se achaca a quiebra. Tampoco la suerte sonreía a los mayordomos, pues cuando se les requirió la mitad de la quiebra a cada uno, 45. 283 mrs., se libró una carta de pago a Pero Nuñez de Guzmán, teniente de alguacil mayor, para que diese los dichos $45.283 \mathrm{mrs}$. «de los dozientas mill mrs... enbargados de los bienes del dicho Alemán Pocasangre», y otra al tesorero veinticuatro Luis de Medina, como secuestrador de los bienes de Tomás de Jaén, para que hiciese lo mismo con los bienes retenidos a Tomás de Jaén. Las dos cartas de pago llevan fecha de 5 de junio de $1482^{4}$.

4 A. M. S., Mayordomazgo, 1481-1482. 
El 5 de noviembre de 1483 los mayordomos consiguieron que se les tomaran en cuenta $126.070 \mathrm{mrs}$. resultantes de la quiebra de Juan de Herrera, en quien se había rematado en 1481 la renta de las imposiciones de la ciudad sin contar las seis villas, arrendador que «se absentó e fue d'esta çibdad» y que, curiosamente, no figura en la lista de escapados transcrita más arriba ${ }^{5}$, como tampoco quedan registrados en ella otros personajes que consta por otros documentos que pusieron asimismo pies en polvorosa. Efectivamente, hay otro documento todavía que alude al susto tremendo de $1480-1481$, pues a la fuga y a los efectos de la inquisición ha de atribuirse una notabilísima apostilla que remata la nómina del mayordomo en 1480, en la que tras la enumeración de salarios se apunta ${ }^{6}$ :

De los cuales se quitan que no han de pagar los dichos mayordomos estos mrs. que se siguen:

- a Diego de Susán iiU ccc

- a Pedro de Córdova iiU $\operatorname{cccc}^{\circ}$

- a Gonçalo de la Puerta vU ccii

- a Diego de la Torre viiU deccc ${ }^{\circ}$

- al dotor Juan Rodríguez iiU

- al liçençiado de la Barrera iiiU

- al dotor Alonso Rodríguez iiU

— al dotor maestre Pedro [de Aslor, físico] iiii ${ }^{\circ} \mathrm{U}$

- al jurado Fernando Çisbón iU

- al jurado Ganso (?) iU

- al jurado Fernand Gómez decc ${ }^{\circ}$

- a Luis de Sevilla iU

- a Luis de Jahén iU

Encabeza esta lista de suspensos de sueldo $-\mathrm{y}$ sin duda de empleo- el famosísimo Diego de Susán, el caballero veinticuatro, sobre cuya «conjura» ha de arrojar intensa luz un artículo en prensa de J. Ollero; siguen otros personajes como el licenciado de la Barrera y el doctor Rodríguez, que sabían compaginar las leyes con las alcabalas. Aparece asimismo un jurado, Fernando Cisbón, pariente sin duda de los mercaderes Manuel y Bartolomé Cisbón, cuya estirpe habría de unirse en el futuro a la familia del licenciado Romero, y de paso también a la de Antonio de Lebrija. De los arrendadores fugados reclama la atención Fernando de las Casas, pariente - pero no padre ni abuelo- del futuro defensor de los indios, así como Luis de Jaén, hermano del propio mayordomo Tomás de Jaén. En las escribanías de Sevilla se conserva un poder dado a Gómez de Córdoba por el judío Mosé Alpalas el 10 de julio de $1480^{7}$.

Aún resta por hablar de otra venerable reliquia de aquella época, exhumada ésta de otro archivo. En efecto, del terrible desconcierto que cundió en 1480-1481 entre los conversos y del desgarrador drama que vivieron algunos de ellos, que

5 A. M. S. Mayordomazgo, 1481-1482.

6 A. M. S. Mayordomazgo, 1480.

7 Cf. K. Wagner, Regesto de documentos del Archivo de Protocolos de Sevilla referentes a judíos y moros, Sevilla, 1978, p. 45, n. 168. 
eran cristianos de corazón, puede darnos ahora buena cuenta el caso del bachiller Fernando Díaz de Medina, hijo de otro huido, Sancho Díaz de Medina, que vio cómo los bienes de su padre eran embargados por el delito de la herética pravedad y que, cuando intentó defender su derecho ante los tribunales, recibió en 1482 una tajante cédula de los monarcas que era de este tenor:

El rey e la reina. Bachiller Fernando Díaz de Medina. Nos avemos sabido cómo avéis enbaraçado e enbaraçais los bienes que fueron de vuestro padre, diziendo que vos perteneçen e alegando otras cabsas e razones injustas; e aun sobre ello diz que a vuestro pedimiento se ha movido pleito sobre los dichos bienes, de lo cual avemos avido enojo e sentimiento de vos. Por ende nos vos mandamos que luego vos desistá1s de la dicha demanda e no vos entremetáis más en le enbaraçar ni ocupar los dichos bienes por ninguna vía al dicho liçençiado nuestro alcalde, pues son confiscados a la nuestra cámara e no tenéis ninguna justiçia ni derecho a ellos, çertificándovos que, si lo contrario fiziéredes, e en ello ensistís más, mandaremos proveer en ello como cunple a nuestro servicio e vos seáis castigado. De Córdova, a primero día de otubre de $\mathrm{xxx}^{\circ} \mathrm{ii}$ años. Yo el rey. Yo la reina. Por mandato del rey e la reina Pedro Camuñas.

El ansia de rapiña daba alas, según se ve, al ardor de los confiscadores. Clamó el bachiller, removió Roma con Santiago, consiguió de Sixto IV una reposición y hasta logró que los inquisidores de Sevilla le expidieran en 1487 un curiosísimo certificado de buen cristiano, capacitándolo, por consiguiente, para desempeñar cargos concejiles, escrito que reza como sigue:

Nos, frey Miguel de Morillo, maestro en Santa Teología, e frey Juan de San Martín, presentado en Santa Teología, de la Orden de los Predicadores del Señor Santo Domingo, juezes inquisidores de la herética pravedad dados e deputados por la Santa See Apostólica, por cuanto somos informados de personas fidedignas que vos, el bachiller Fernando Díaz de Medina, vezino de la çibdad de Sevilla, fijo de Sancho Díaz de Medina, avéis bivido fiel e cathólicamente como fiel e cathólico christiano, e fasta agora de lo contrario aquesto no avemos tenido ni tenemos contra vos informaçión, declaramos por la presente que podéis usar e exerçer los ofiçios públicos e privados e fazer todas las cosas que a los fieles e católicos christianos semejantes a vos son permetidos e deven usar e fazer, sin enbargo del proçeso que ante nos se fizo contra el dicho vuestro padre e en su absençia, e de la sentençia que contra él se dio e del mandamiento por nos en su execuçión dado, por cuanto todo aquello fue repuesto en el estado en que estava antes qu'el dicho proçeso se fiziese e la dicha sentençia se diese, segund paresçe por los proçesos que çiertos auditores de nuestro muy Santo Padre Sexto cuarto dados e en la dicha cabsa fechos e fulminados. Fecha veinte e cuatro del mes de novienbre, año del nasçimiento de nuestro Salvador Jhesuchristo de mill e cuatroçientos e ochenta e siete años. Frater Michael inquisitor. Frater Ioannes de S. Martin inquisitor. Franciscus doctor. Por mandado de los muy reverendos señores inquisidores Estevan de Badajoz, público notario.

La reclamación hubo de tener, sin embargo, poco éxito o el bachiller y su familia debieron ser considerados como pecheros a la hora de la famosa composición con Fernando el Católico, pues el 6 de octubre de 1515 presentó las cédulas originales ante el escribano Juan Núñez, para que diese la fe correspondiente, un 
hijo del bachiller - ya difunto para entonces-, Gonzalo Díaz Medina, que residía en la collación de San Esteban, prueba aparente de que la causa no había llegado a un final satisfactorio para todos. Pero tampoco cabe descartar que la copia ante escribano se debiese a motivos de herencia, ya que el 2 de octubre del mismo año había otorgado su última voluntad la madre y esposa de Fernando Díaz de Medina, Beatriz López ${ }^{8}$. En cualquier caso, gracias a este testamento nos enteramos de que Gonzalo, casado con Isabel Dávila, había tenido que mantener de su bolsillo durante diez años a sus padres, que le debían unos $110.000 \mathrm{mrs}$., y que se había gastado asimismo unos 20.000 mrs. «en fazer la ystoria de Sant Matías apostol delante de la sepultura» del bachiller, sin recibir nada a cambio. Pero estas ostentosas exequias, demostrativas de profunda piedad, no convencían ni a los cristianos viejos ni a los conversos, pues otro hijo del bachiller, Sancho Díaz de Medina, andaba fuera de Sevilla, sin que la madre supiese de él, probablemente escondido en casa de algún familiar si es que no se había dedicado a la vida de pícaro.

Interesa destacar, por último, que los huidos en 1481, tras los primeros autos de fe, no son propiamente los judíos, sino los conversos, angustiados ante la idea de verse sometidos a un examen riguroso sobre la pureza de sus creencias religiosas. En efecto, en 1483 vemos aparecer a conspicuos hebreos haciéndose cargo de las rentas. Así, por ejemplo, en el vecino de Sevilla Don Isaque Abenzemerro ${ }^{9}$ se remató en ese año lo siguiente: la imposición de la madera en 830.000 mrs.; la imposición de los pescados en 550.000 mrs.; el cornado de la carne en 250.000 mrs. y la renta de la saca de los cueros en 31.000 mrs. A su vez, en Juan Alemán, vecino del barrio de Castellanos, se remató la imposición de la Sierra en 820.000 mrs.; la blanca de la libra de la carne en 500.000 mrs. y el cornado de la carne en Triana, Cestería y Carretería en $190.000 \mathrm{mrs} .{ }^{10}$. He aquí, pues, la prueba más contundente de todas de que la mayor parte, si no la totalidad de los arrendamientos estaba en manos de los judíos y cristianos nuevos. En definitiva, gracias a las cuentas del mayordomo de Sevilla conocemos no sólo la magnitud del desastre económico y sus consecuencias, muchas veces puestas de relieve un tanto a boleo, sino hasta los nombres de algunos de los principales conversos de la ciudad, en una época primeriza en la que no abundan los testimonios sobre la Inquisición.

8 Todas las escrituras se hallan en el Archivo de Protocolos de Sevilla, Oficio VI, año 1515. Hijos de Beatriz fueron Gonzalo, Catalina, Constanza, Luis y Sancho. Catalina, dotada con 23.000 mrs., casó con Pedro Fernández de Sevilla. Constanza, ya muerta en 1515, aportó una dote de 30.000 mrs. al matrimonio con Francisco de Herrera, de quien tuvo tres hijos, Sancho, Isabel y Beatriz. Gonzalo tuvo una hija natural, Isabel Ruiz. De Luis, ya fallecido, quedaba otro hijo natural, también llamado Luis. Otorgó codicilo Beatriz López el 26 de octubre de 1515, revocando el tercio con que había mejorado a Gonzalo.

9 Dan noticias de él y de su actividad como arrendador los protocolos de Sevilla (cf. K. Wagner, Regesto, índice, s. u.).

10 A. M. S., Mayordomazgo, 1483. 
